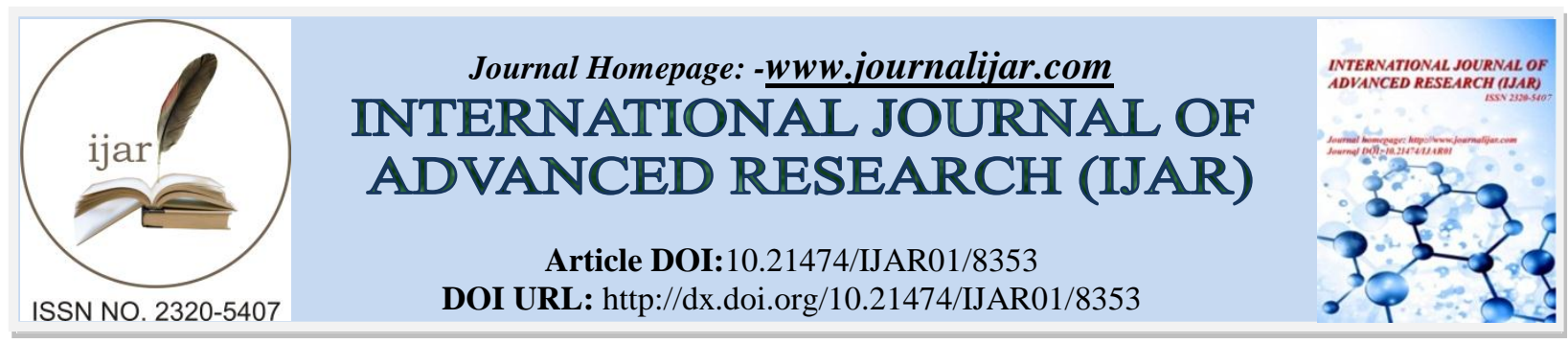

RESEARCH ARTICLE

\title{
A STUDY OF CONSUMER BEHAVIOUR TOWARDS ONLINE SHOPPING WITH SPECIAL REFERENCE TO BANGALORE CITY, KARNATAKA - INDIA.
}

Chandan A.

Mba, net.planning executive in aquarelle india pvt ltd. (textile company).

\section{Manuscript Info}

Manuscript History

Received: 08 November 2018

Final Accepted: 10 December 2018

Published: January 2019

\section{Abstract}

Electronic commerce, commonly known as e-commerce, refers to the buying and selling of products or services over electronic systems such as the internet and other computer networks. Internet is the rapidest growing media during the past decade. It has changed the look of new era. Especially, online shopping is a rapidly growing e- commerce area. Online stores are usually available 24 hours a day, and many consumers have internet access both at work and at home. A successful web store is not just a good looking website with dynamic technical features, listed in many search engines but it always looks forward for consumer satisfaction. This study aims to establish a preliminary assessment, evaluation and understanding of the characteristics of online shopping. An effort has been made to investigate online consumer behaviour, which in turn provides E-marketers with a constructional framework for fine-tuning their E-businesses' strategies.

Copy Right, IJAR, 2017,. All rights reserved.

\section{Introduction:-}

Internet is changing the way consumers shop and buy goods and services and has rapidly evolved into a global phenomenon. Many companies have started using the Internet with the aim of cutting marketing costs, thereby reducing the price of their products and services in order to stay ahead in highly competitive markets. Companies also use the Internet to convey, communicate and disseminate information, to sell the product, to take feedback and also to conduct satisfaction surveys with customers. Customers use the Internet not only to buy the product online, but also to compare prices, product features and after sale service facilities they will receive if they purchase the product from a particular store. Many experts are optimistic about the prospect of online business. In addition to the tremendous potential of the E-commerce market, the Internet provides a unique opportunity for companies to more efficiently reach existing and potential customers. It has been more than a decade since business-to-consumer E commerce first evolved. Scholars and practitioners of electronic commerce constantly strive to gain an improved insight into consumer behaviour in cyberspace.

\section{Review ofLiterature: -}

Solomon (1998) studied the Consumer behaviour and said that it is the study of the processes involved when an individual select, purchases, uses or disposes of products, services, ideas, or experiences to satisfy needs and desires. In view for the Internet to spread out as a retail channel, it is imperative to realize the consumer's mind set, intention and conduct in light of the online buying practice.

\section{Corresponding Author:-Chandan A.}

Address:-Mba, net.planning executive in aquarelle india pvt ltd. (textile company) 
Lepkowska-White, and Rao (1999) preferred vendor characteristics, security of transactions, content for privacy and customer characteristics as factors influencing electronic exchange.

Donthu and Garcia (1999) proposed that risk aversion, innovativeness, brand consciousness, price consciousness, importance of convenience, variety-seeking propensity, impulsiveness, attitude toward advertising, attitude toward shopping, and attitude toward direct marketing would influence online shopping behaviour.

Schiffman, Scherman, \&Long (2003) in his study researched that "yet individual attitudes do not, by themselves, influence one's intention and/or behaviour. Instead that intention or behaviour is a result of a variety of attitudes that the consumer has about a variety of issues relevant to the situation at hand, in this case online buying. Over time the Internet buyer, once considered the innovator or early adopter, has changed. While once young, professional males with higher educational levels, incomes, tolerance for risk, social status and a lower dependence on the mass media or the need to patronize established retail channels (Ernst \& Young, 2001; Mahajan, Muller \& Bass, 1990),

Sultan and Henrichs (2000) in his study concluded that the consumer's willingness to and preference for adopting the Internet as his or her shopping medium was also positively related to income, household size, and innovativeness.

Vijay, Sai. T. \& Balaji, M. S. (May 2009), revealed that Consumers, all over the world, are increasingly shifting from the crowded stores to the one- click online shopping format. However, in spite of the convenience offered, online shopping is far from being the most preferred form of shopping in India. A survey among 150 internet users, including both users and non-users of online shopping, was carried out to understand why some purchase online while others do not. The results suggested that convenience and saving of time drive Indian consumers to shop online; while security and privacy concerns dissuade them from doing so.

The work of Kim and Park (2005) using U.S. samples suggests that their positive attitudes as well as willingness to search for pre-purchase information leads to a strong likelihood that they will buy online. Online shoppers, are required to have computer skills in order to use the Internet for shopping. Hence, those who are not comfortable with using the computer, will likely do their shopping at the traditional store, modern shop, or discount store (Monsuwe, 2004) because it will be faster shopping there than in the Internet shop.

Goldsmith and Flynn (2004) state that the home catalog is another traditional selling channel where people can shop at home because of the varieties of products offered in the catalog. They can order through the phone or by mail. It is convenient except that they are not able to touch and feel products before purchasing.

\section{Objectives of The Study: -}

The objective of this research study is to investigate online consumer behaviour, which in turn provides E-marketers with a constructional framework for fine-tuning their E-businesses' strategies. The specific objectives of this research are:-

1. To analyse the consumer's awareness about online shopping.

2. To know the various factors which motivate a consumer towards online shopping.

3. To analyse the kind of goods they purchase online.

4. To know the problems they face during online shopping.

\section{Research Methodology: -}

The research is based upon primary and secondary data both. The primary data was collected through a questionnaire designed exclusively for the study. Secondary data was taken from research papers, Journals, magazines and websites.

\section{Sample size and area: -}

Samples were collected from consumers and buyers of online shopping of Bangalore city. A target of 100 respondents was set, and all of them return complete questionnaire with their suitable choice. Therefore, all 100 questionnaires were entertained for final analysis and data interpretation. 
Tools for analysis: -

For data analysis, simple charting and tabulation tools are used to understand the behaviour of the respondents for online shopping.

Analysis andInterpretation:-

Age: -

\begin{tabular}{|c|c|c|c|}
\hline Less than 20 & $20-30$ & $30-40$ & Above 40 \\
\hline 6 & 68 & 18 & 8 \\
\hline
\end{tabular}

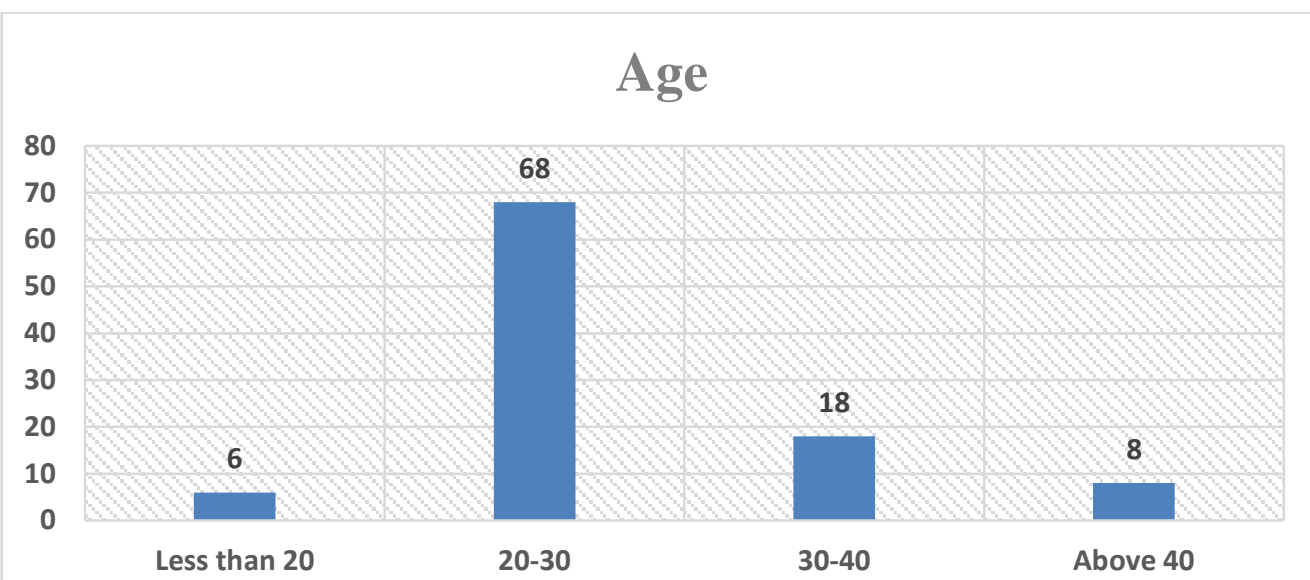

Figure 1:-From the above diagram, it is interpreted that maximum respondents are from the age between 20 to 30 where as the respondents of age between 30 to 40 are relatively low.

\section{Occupation: -}

Occupation: -
\begin{tabular}{|c|c|c|c|}
\hline Government Employees & Private Sector & Self Employed & Others \\
\hline 8 & 32 & 12 & 48 \\
\hline
\end{tabular}

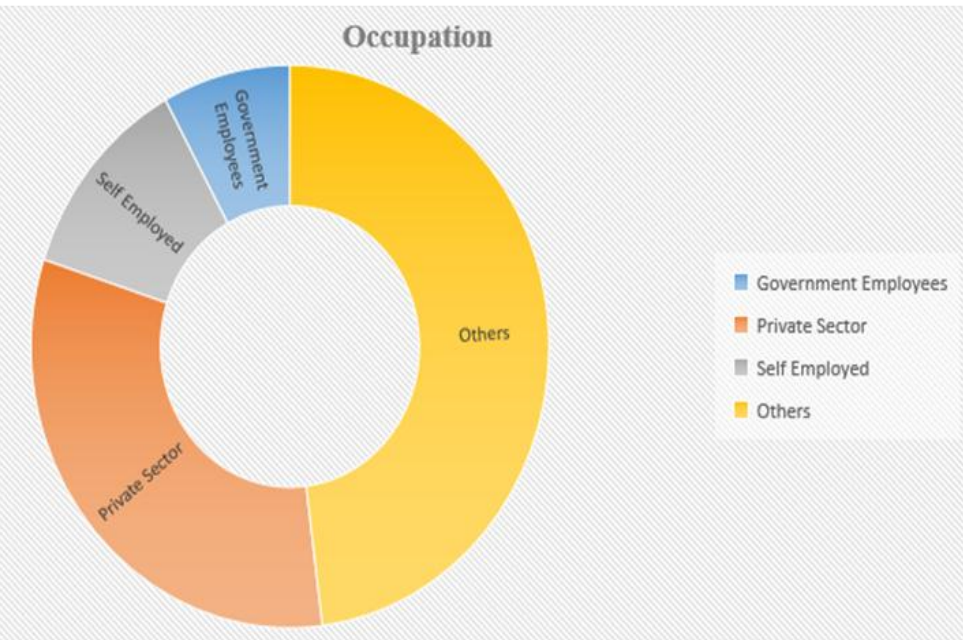

Figure 2:-The above figure shows that the occupation of maximum shoppers falls under the category of others which consist of students and other occupations. The second highest category of online shoppers is having the occupation of private sector.

Average Annual Family Income: -

\begin{tabular}{|c|c|c|c|}
\hline Less than 50000 & $50000-2$ lakh & 2lakh - 5lakh & Above 5lakh \\
\hline 16 & 23 & 47 & 14 \\
\hline
\end{tabular}




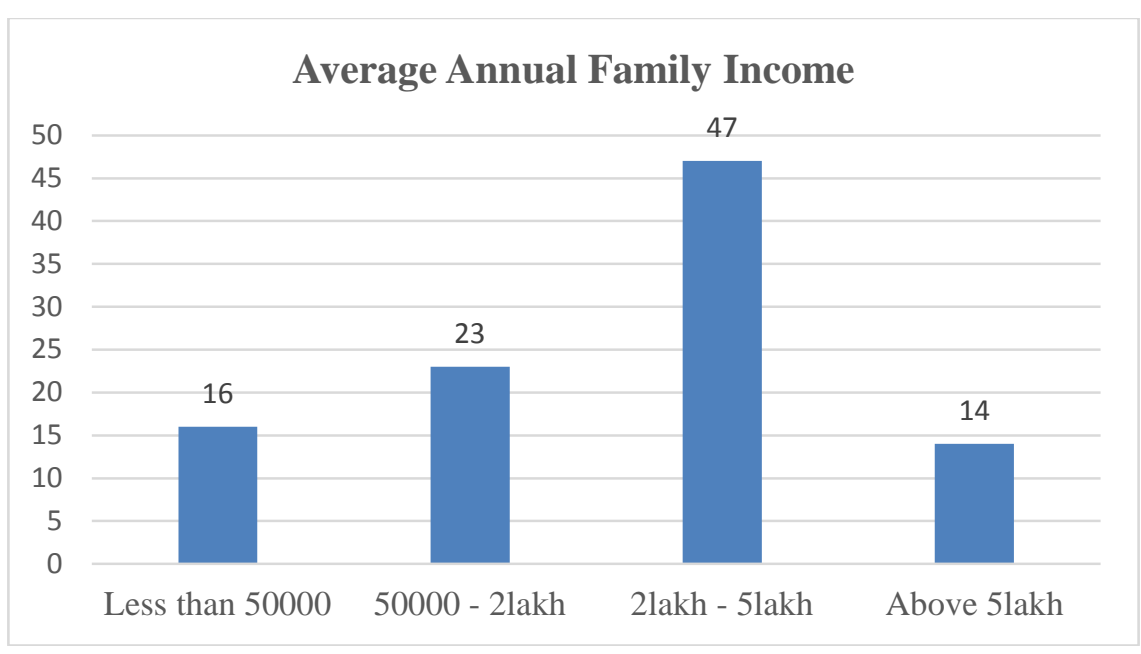

Figure 3:-The above chart and diagram shows that the shoppers having average family income in between 2lakh 5lakh per annum gives more preference to online shopping. This may be because of attractive discounting offers offered by shopping sites. Also the shoppers whose annual family average income is in between 50,000-2lkh also spends more on online shopping.

Using Internet from: -

\begin{tabular}{|c|c|c|c|}
\hline Less than one year & $1-2$ years & $2-4$ years & More than 4 years \\
\hline 2 & 6 & 18 & 74 \\
\hline
\end{tabular}

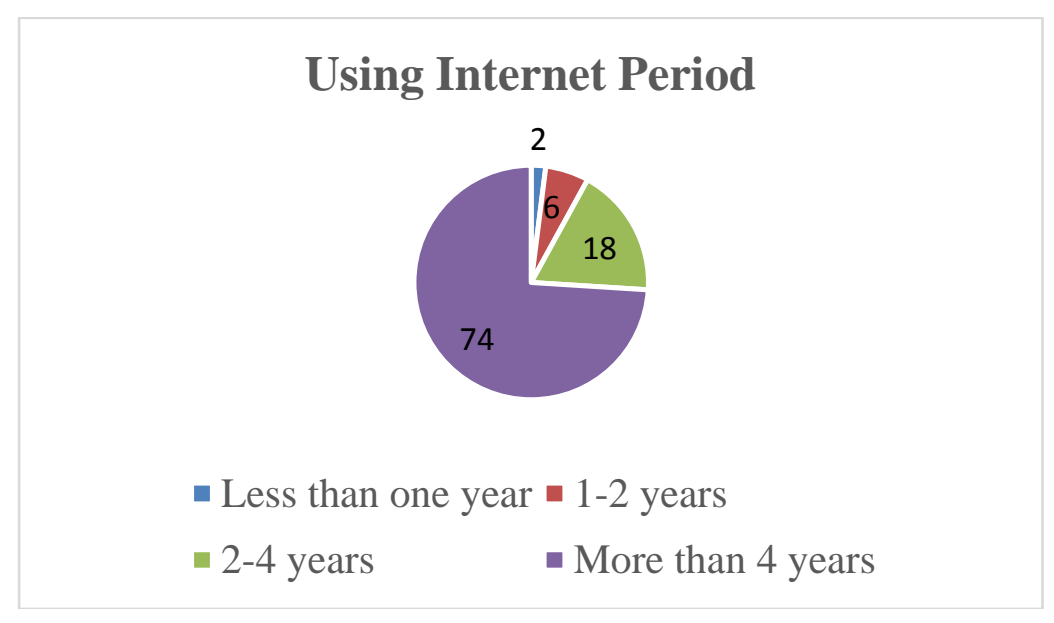

Figure 4:-It is interpreted that out of the total respondents $2 \%$ are using the internet less than a year. $6 \%$ of the respondents are using for the past 1-2 years. $18 \%$ of the respondents are using internet for the past 2-4 years whereas majority of respondents that is $74 \%$ have been using the internet for more than 4 years.

\section{Usage of internet for Online Shopping: -}

\begin{tabular}{|c|c|c|c|}
\hline Never & Occasionally & Often & Very Often \\
\hline 6 & 46 & 28 & 20 \\
\hline
\end{tabular}




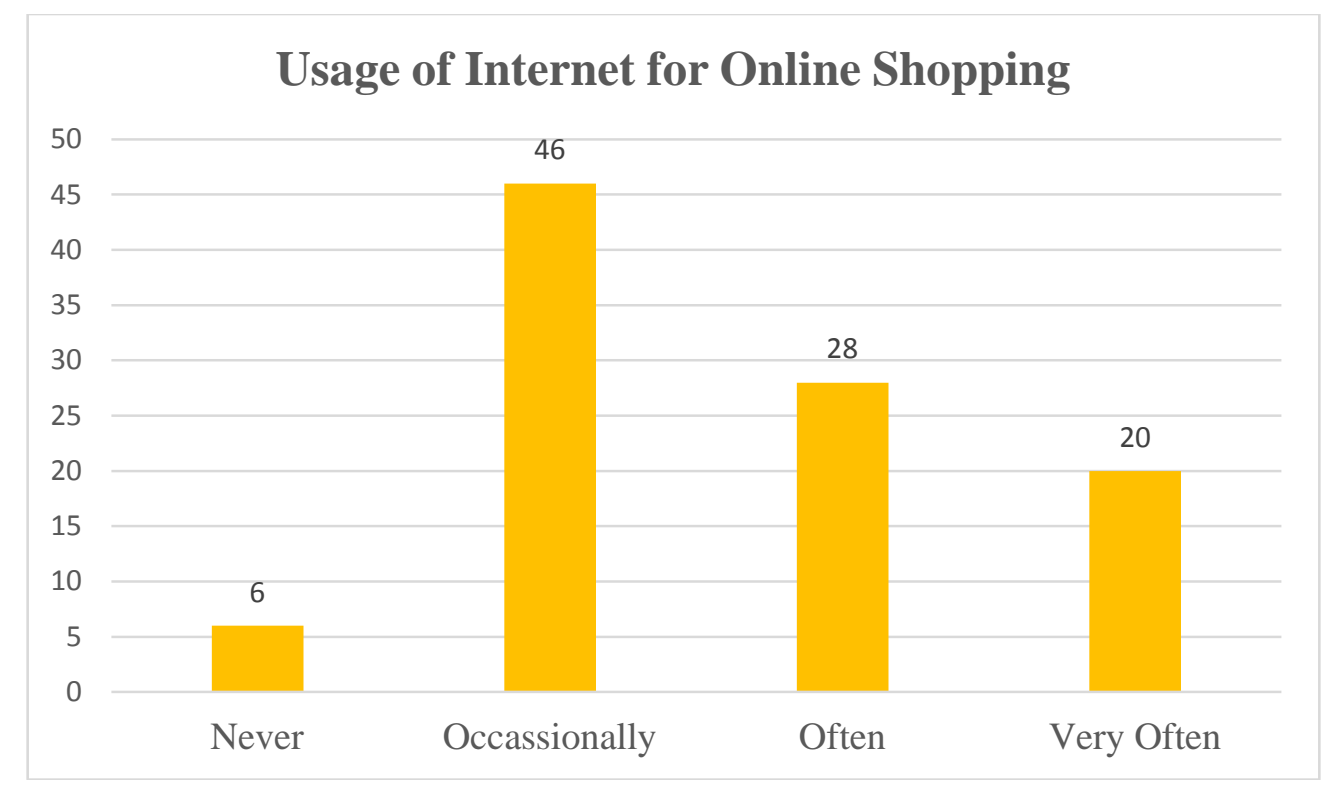

Figure 5:-The above chart shows that $46 \%$ of the respondents use internet occasionally whereas $28 \%$ use often and $20 \%$ use internet very often.

Which factor Motivates for Online Shopping: -

\begin{tabular}{|c|c|c|c|c|}
\hline Saves time & Convenience & Price & Product Quality & Not Applicable \\
\hline 55 & 15 & 15 & 14 & 1 \\
\hline
\end{tabular}

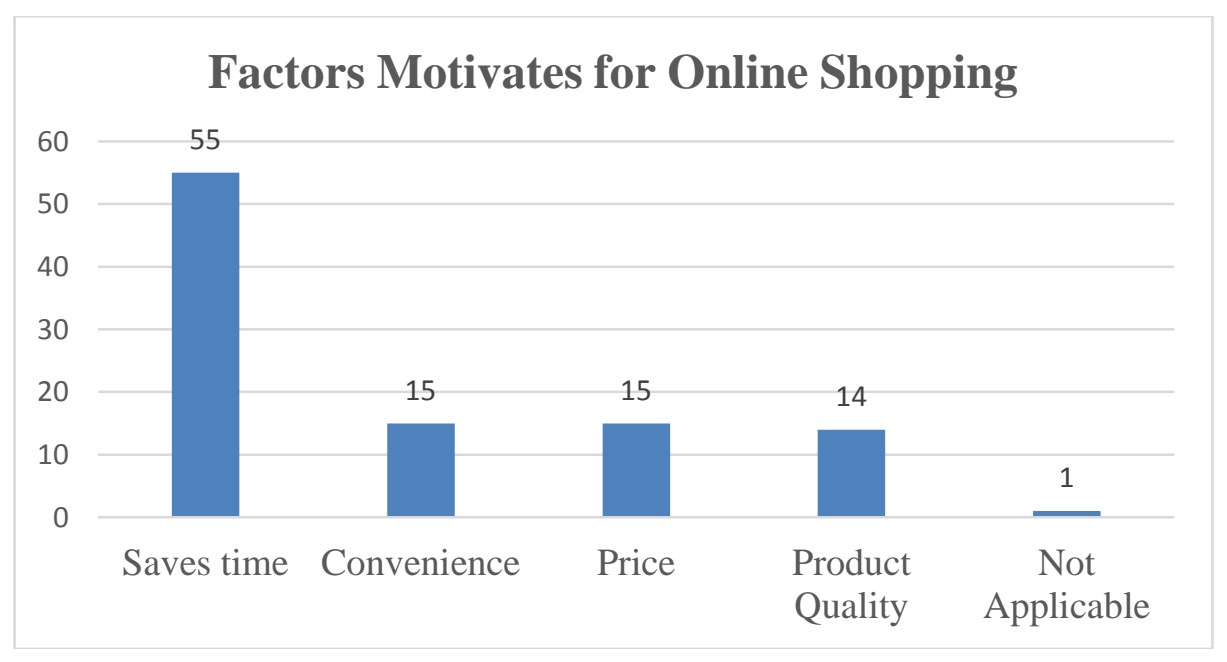

Figure 6:-The study showed that 55\% of the shoppers prefers online shopping as it saves time whereas $15 \%$ shoppers gets attracted towards prices offered. $15 \%$ shoppers who think convenience is the main driving force while $14 \%$ of the shopping had been done for whom quality was the main orientation for shopping online.

Kinds of Goods Purchased through Online Shopping: -

\begin{tabular}{|c|c|c|c|c|c|}
\hline Electronic goods & Cloths & Fashion Accessories & Books & Tickets & Others \\
\hline 22 & 20 & 20 & 8 & 17 & 13 \\
\hline
\end{tabular}




\section{Kinds of Goods Purchased Through Online Shopping}

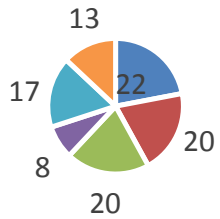

- Electronic goods - Cloths

- Fashion Accessories • Books

- Tickets $\quad$ Others

Figure 7:-It is depicted in the chart that the highest category of goods purchased by the respondents (22\%) is Electronic goods and clothes. Fashion accessories are having similar demand among online shoppers. Whereas the lowest category of goods purchased online are books and others.

Medium Preferred for Online Shopping: -

\begin{tabular}{|c|c|c|c|}
\hline Laptop/Desktop(PC) & Tablet & I Pad & Smartphone \\
\hline 14 & 4 & 2 & 80 \\
\hline
\end{tabular}

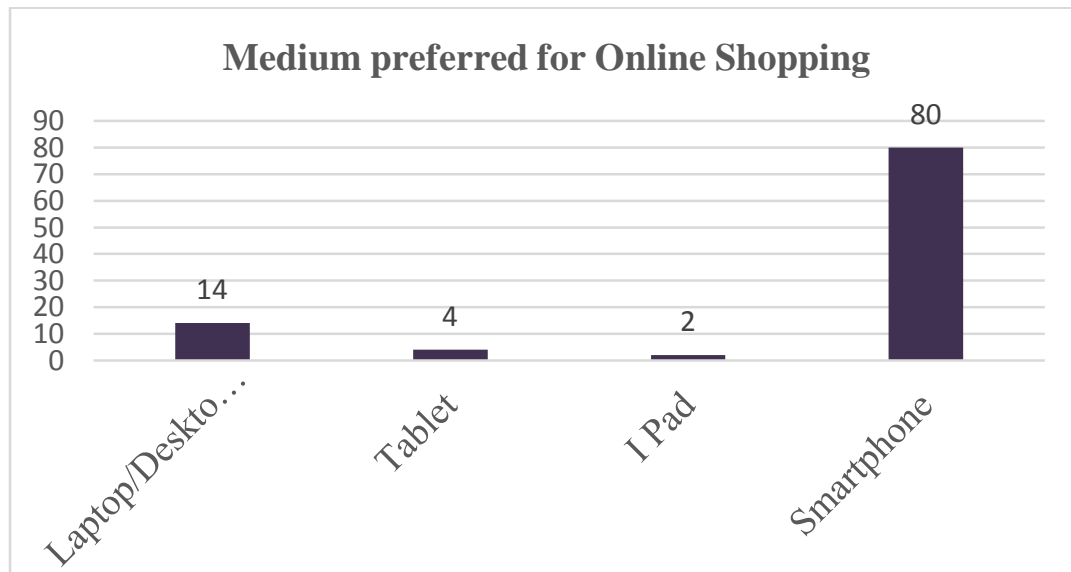

Figure 8:-ccording to the chart $80 \%$ of the respondents use Smartphone for online shopping, $14 \%$ use laptop and PC, $4 \%$ use tablets whereas $2 \%$ use I pads for online shopping.

Is the Information given about the product on site sufficient?-

\begin{tabular}{|c|c|c|c|c|}
\hline Strongly Disagree & Disagree & Neutral & Agree & Strongly Agree \\
\hline 4 & 5 & 38 & 48 & 5 \\
\hline
\end{tabular}




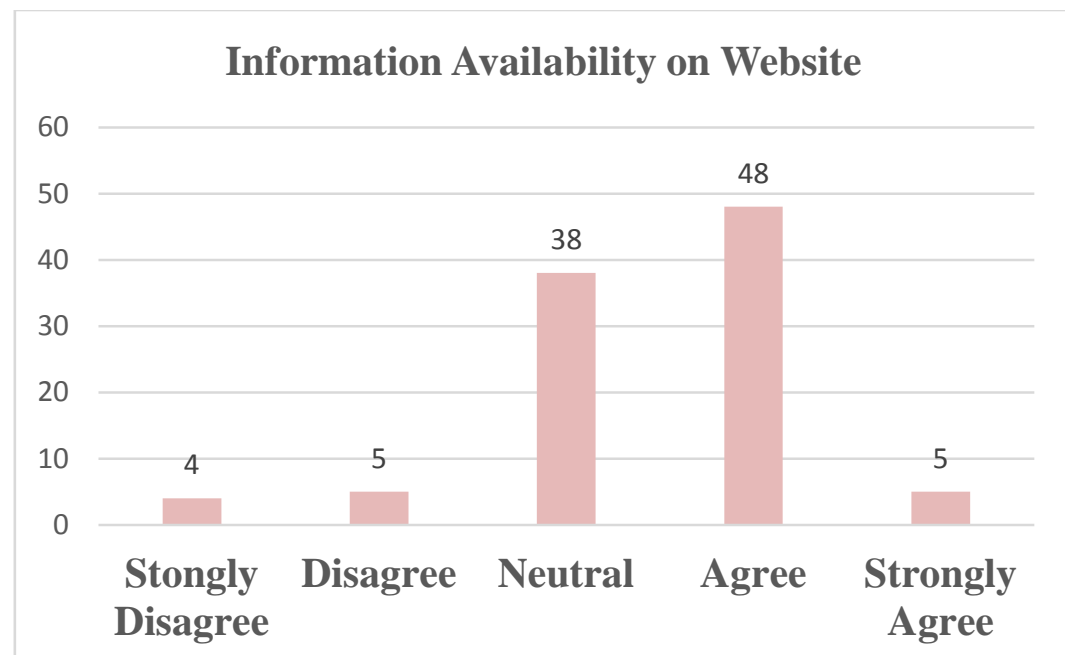

Figure 9:-According to the study, it is depicted that $5 \%$ of the respondents strongly agree that the information given about the product on the site is sufficient. $48 \%$ of the respondents agree with the statement, $38 \%$ are neutral, $5 \%$ disagree whereas $4 \%$ of the respondents strongly disagree with the statement.

Favourite Online Shopping Site:-

\begin{tabular}{|c|c|c|c|c|}
\hline Amazon & Flipkart & Snap deal & Myntra & Others \\
\hline 42 & 22 & 17 & 11 & 8 \\
\hline
\end{tabular}

\section{Favourite Online Shopping Website}

Figure 10:-According to the research, $42 \%$ of the respondents prefer Amazon, 22\% prefer Flipkart, $17 \%$ prefer snap deal, and $11 \%$ prefer Myntra, whereas $8 \%$ prefer other sites for online shopping.

Methods Used for Making payment: -

\begin{tabular}{|c|c|c|c|}
\hline Credit/Debit cards & Cash on Delivery & Bank transfer & Others \\
\hline 24 & 70 & 6 & 0 \\
\hline
\end{tabular}




\section{Methods Used for Making Payments}

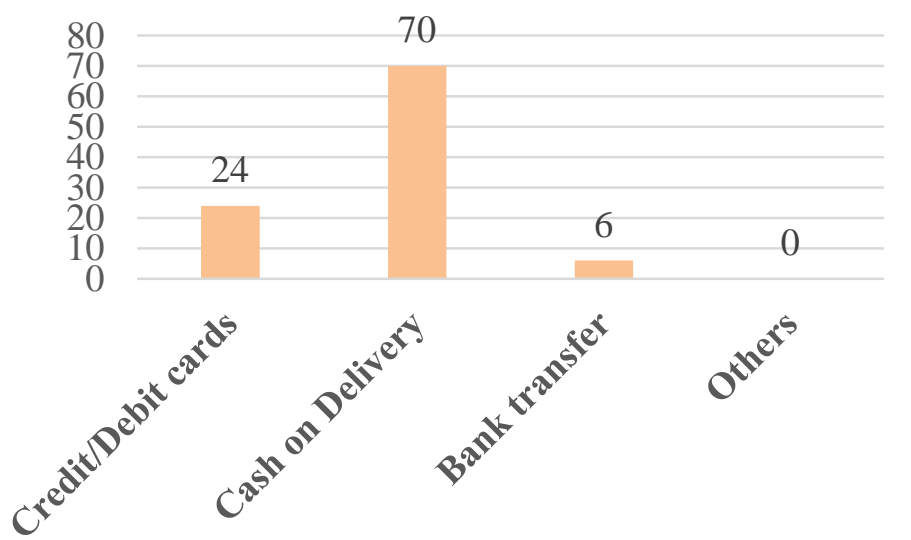

Figure 11:-The above chart depicts that majority of the respondents that is $70 \%$ use cash on delivery option for payment, 24\% use credit/Debit cards, $6 \%$ use bank transfer, and other methods of payment for online shopping.

Satisfaction Level of Online Shopping: -

\begin{tabular}{|c|c|c|c|}
\hline Not Satisfied & Satisfied & Very much Satisfied & Can't Say \\
\hline 6 & 64 & 12 & 18 \\
\hline
\end{tabular}

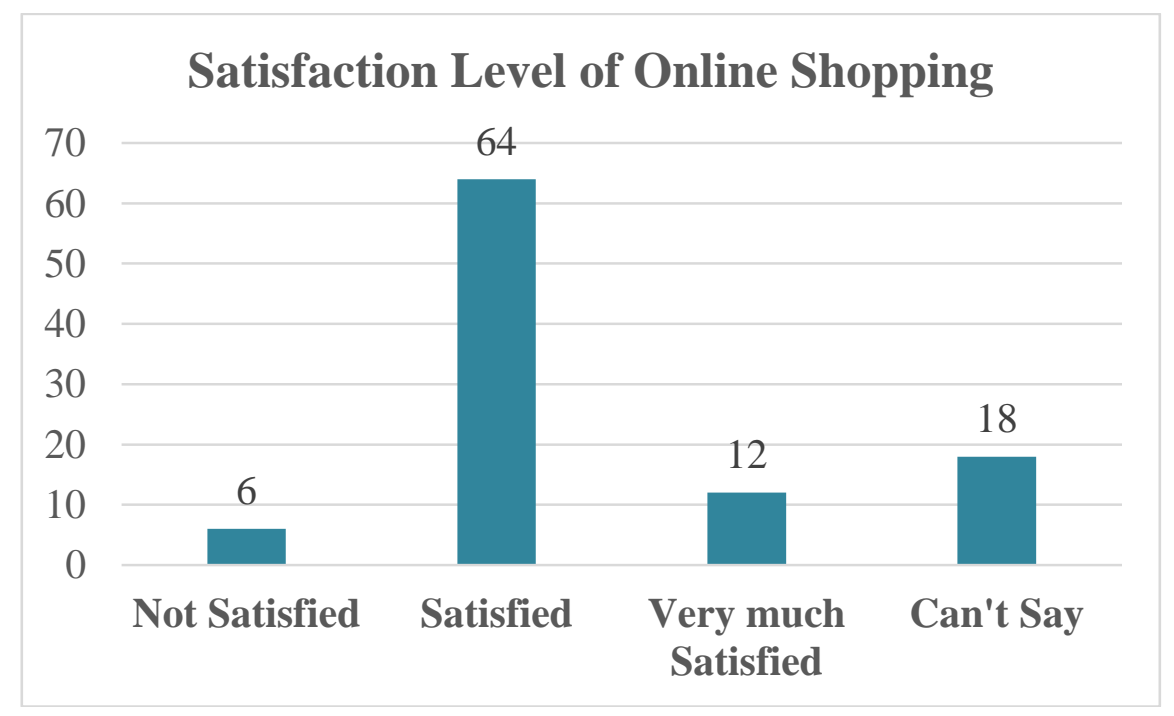

Figure 12

The study helped to found out that $64 \%$ of the respondents were satisfied with online shopping, $6 \%$ were not satisfied, and $18 \%$ were neutral whereas $6 \%$ of the respondents were not satisfied with online shopping.

Problems faced in Online Shopping:-

\begin{tabular}{|c|c|c|c|}
\hline Problay in delivery & Low Quality & Product Damage & Other \\
\hline 42 & 28 & 14 & 16 \\
\hline
\end{tabular}




\section{Problems faced in Online Shopping}

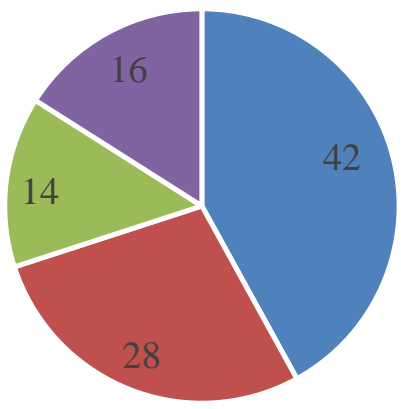

- Delay in delivery - Low Quality

- Product Damage - Other

Figure 13:-According to the chart $42 \%$ of the respondents felt the delay in delivery as the problem of online shopping. $28 \%$ of the respondents regard low quality product as the problem. $14 \%$ of the respondent's regard product damage to be one of the problems of online shopping whereas $16 \%$ feel that there are other problems associated with online shopping.

\section{Approximate Amount to be spent on Single purchase (in Rs.): -}

\begin{tabular}{|c|c|c|c|c|}
\hline Apss than 1000 & $1000-3000$ & $3000-5000$ & $5000-10000$ & More than 10000 \\
\hline 32 & 36 & 14 & 12 & 6 \\
\hline
\end{tabular}

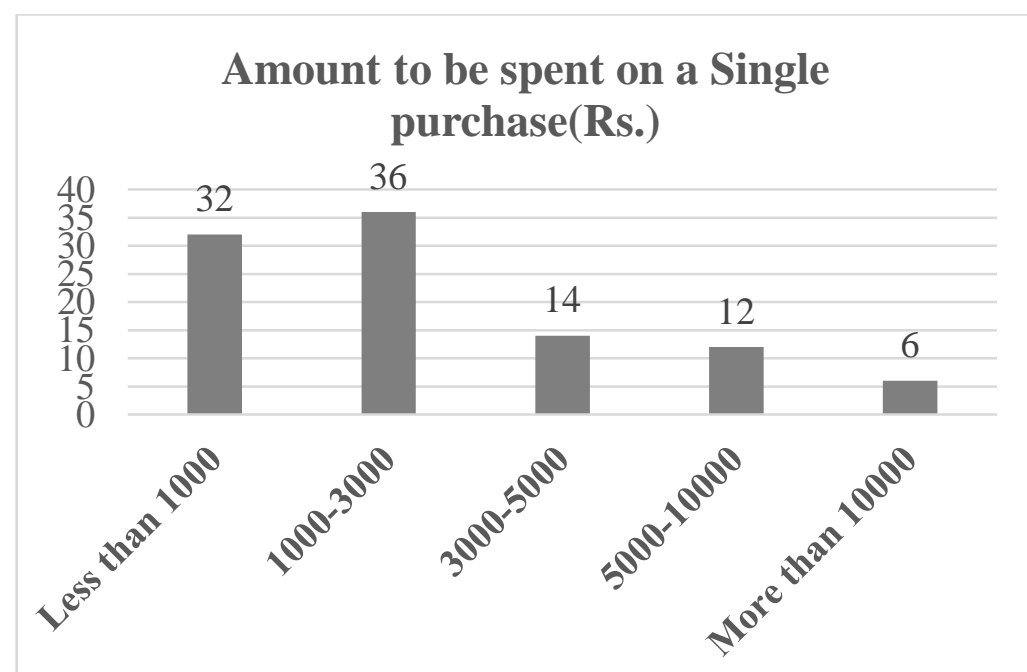

Figure 14:-The approximate amount willing to be spent on a single online purchase by majority of the respondents that is $36 \%$ is around Rs $1000-3000.32 \%$ of the respondents are ready to spend less than 1000 whereas $12 \%$ are ready to spend around Rs5000-10000. The \% of respondents who are willing to spend $3000-5000$ is $14 \%$ whereas $6 \%$ of therespondents are ready to spend more 10,000 on a single purchase. 
Satisfied Level of Product return policy: -

\begin{tabular}{|c|c|c|c|}
\hline Very much Satisfied & Satisfied & Not-Satisfied & Can't say \\
\hline 12 & 54 & 8 & 26 \\
\hline
\end{tabular}

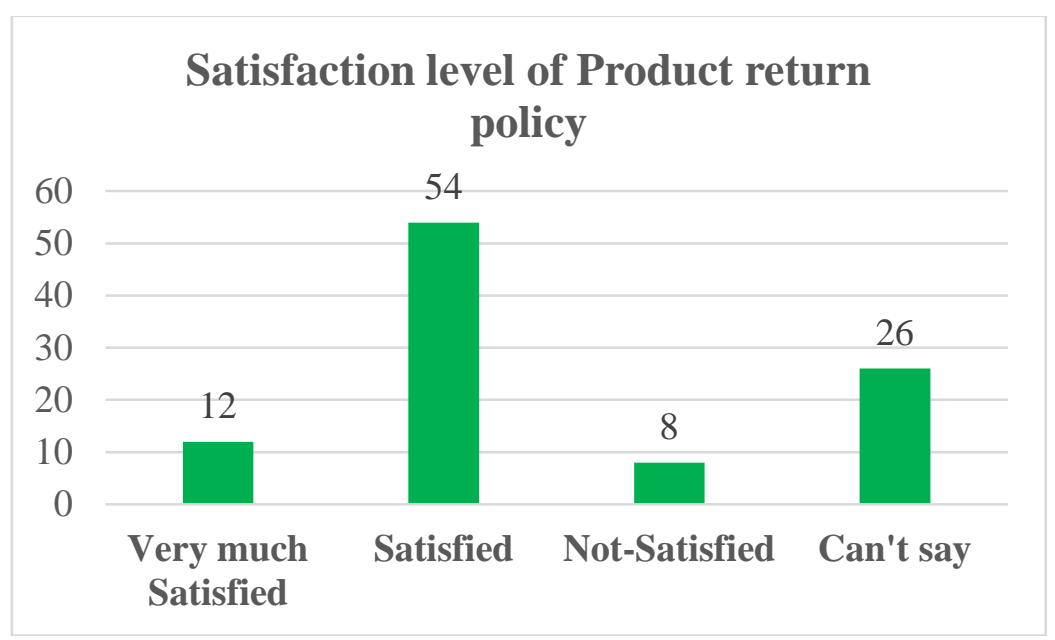

Figure 15:-From the above chart and diagram it is clear that maximum respondents that $54 \%$ are satisfied with the product return policy of online shopping whereas $26 \%$ of the respondents are neutral about return policy.

\section{Findings: -}

1. Most of the online shoppers are in between the age of 20 to 30 years.

2. The shoppers having average annual family income between Rs 200000 to 500000 preferred online shopping.

3. Most of the online shoppers are using internet for more than four years.

4. The analysis showed that the shoppers use internet for online shopping occasionally.

5. The most important motivating factors which influence the online shopping are time saving, convenience and price.

6. Among the goods purchased through online shopping clothes, electronic goods and fashion accessories are more demandable.

7. Most of the online shoppers used smart phone as a medium for online shopping.

8. Majority of the respondents that is $48 \%$ agree that the information given about the product on various sites are sufficient for the consumer. $38 \%$ of the respondents are neutral, 5\% are disagree whereas 5\% as strongly disagree.

9. Amazon is the most favourite shopping site of the respondents.

10. Among the various option of payment available online cash on delivery is the most common method use for payment whereas, bank transfer is the least common method of online shopping.

11. According to the analyses majority of the respondents are satisfied with online shopping.

12. Most of the respondents faced the problem of delay in delivery while online shopping.

13. Majority of the respondents are willing to spend Rs 1000 to 3000 on a single online purchase.

14. Most of the respondents are satisfied with the product return policy of online shopping sites.

\section{Suggestions: -}

1. Some strict action should be taken to prohibit fraudulent online shopping sites.

2. Delivery of the product should be in stipulated time period according to norms on website.

3. Attractive discounting offers should be introducing to attract to more customers for online shopping.

4. In case of some specific goods (like clothes) quality should be the prime concern.

5. In case of mode of payment other technologies like encryption technology trusted third party certifications, digital ID system and pre-paid cards should be used.

6. Most of the Indians still like to see the product before buying, efforts should be made to change this mind set of the people by making them aware of the benefits of online shopping.

7. Innovative service should be provided to consumers for comparing the various products easily and to take buying decisions. 
8. Good after sale service should be provided for the consumers making it an enjoyable experience.

\section{Conclusion: -}

The e-commerce is one of the biggest things that have taken the business by a storm. It is creating an entirely new economy, which has a huge potential and is fundamentally changing the way businesses are done. It is believed that electronic commerce will become a huge industry in the coming years and online shopping is now becoming a significant part of the consumer's daily life to meet their never ending requirements in a convenient way. Online shopping is picking up and is becoming a trend. More consumers are indulging into internet shopping as seen by the research because of the value proposition it offers to a customer such as convenience, $24 \mathrm{x} 7$ shopping, doorstop delivery, a broad product selection and the ever-expanding range of unique and unusual gift ideas as well as increased consumer confidence in shopping on the internet is increasing. The main motivating factor seen during the research was the convenience and customer service which drives the people to online shopping. As a result, today they are buying airline and railway tickets, books, home appliances, electronic gadgets, movie tickets, etc. by logging on to a web site, then driving up to a store. As the research suggests that increase in usage of internet increases the online shopping so there is a need to increase in broadband penetration as it accelerates the growth of online trade. A huge buyers and sellers across demographics are shopping online because of the changing lifestyles and shopping habits. It is seen that despite the immense possibilities available on the internet it is mainly used for mailing, chatting and surfing. E-mail applications still constitute the bulk of net traffic in the country.

\section{References:-}

1. S. Chand 2007 "E- commerce and its applications".

2. Miyazaki, A.D.; Fernandez, A.," Consumer perceptions of privacy and security risks for online shopping”, The Journal of Consumer Affairs, Vol. 35, No. 1, pp. 27-44, 2001.

3. Na Wang, Dongchang Liu, Jun Cheng, "Study on the Influencing Factors of Online Shopping", Proceedings of the 11th Joint Conference on Information Sciences, Published by Atlantis Press, 2008.

4. NorazahMohdSuki, NorbayahMohdSuki, "Cellular Phone Users' Willingness to Shop Online", World Academy of Science, Engineering and Technology International Journal of Social, Human Science and Engineering Vol. 3, No. 6, pp. 70-74, 2009.

5. Rowley, J., "Product searching with shopping bots", Internet Research: Electronic Networking Applications and Policy, Vol. 10, No. 3, pp. 203-214, 2000

6. Schiffman, L.G., Sherman, E., \& Long, M.M., "Toward a better understanding of the interplay of personal values and the Internet", Psychology \& Marketing, 20(2), pp. 169-186, 2003.

7. Solomon, M. R., “Consumer behavior”, New York, NY: Prentice Hall, 1998.

8. Sorce, P.; Perotti, V.; Widrick, S., "Attitude and age differences in online buying”, International Journal of Retail \& Distribution Management, Vol. 33, No. 2/3, pp. 122-132, 2005.

9. Sultan, F., Henrichs, R.B., "Consumer preferences for Internet services over time: initial explorations", The Journal of Consumer Marketing, 17(5), pp. 386-403, 2000. 